\title{
Urgences
}

\section{Un pas de TROIS pour la continuité... Jean Cossette}

Numéro 3, 4e trimestre 1981

URI : https://id.erudit.org/iderudit/025037ar

DOI : https://doi.org/10.7202/025037ar

Aller au sommaire du numéro

Éditeur(s)

Urgences

ISSN

0226-9554 (imprimé)

1927-3924 (numérique)

Découvrir la revue

Citer ce document

Cossette, J. (1981). Un pas de TROIS pour la continuité... Urgences, (3), 5-6.

https://doi.org/10.7202/025037ar

Ce document est protégé par la loi sur le droit d'auteur. L'utilisation des services d'Érudit (y compris la reproduction) est assujettie à sa politique d'utilisation que vous pouvez consulter en ligne.

https://apropos.erudit.org/fr/usagers/politique-dutilisation/
Cet article est diffusé et préservé par Érudit.

Érudit est un consortium interuniversitaire sans but lucratif composé de l'Université de Montréal, l'Université Laval et l'Université du Québec à Montréal. Il a pour mission la promotion et la valorisation de la recherche. https://www.erudit.org/fr/ 


\section{Un pas de TROIS pour la continuité...}

Si à URGENCES le Trois ne fait pas le mois, il se veut toutefois un indice valable de l'importance sans cesse croissante que prend la revue dans l'Est du Québec et déjà outre-frontière régionale. Notre premier but se réalise de numéro en numéro, c'est-àdire passer de la page aux enluminures scripturaires, trop souvent anonyme, à la troisième dimension de la revue-objet et véhicule culturel qui s'installe non seulement au chevet de vos lectures, mais aussi dans l'Eden coloré de votre être en mal de voyages. Pour meubler votre boîte à images, nous vous proposons par ce troisième numéro, un kaléidoscope littéraire particulièrement varié. À vous d'en prendre connaissance à la vitesse qui conviendra à votre croisière.

Pour débuter, Michel Savard nous a fait parvenir une série de clichés réalistes: une percée lucide au gré des saisons et photographié de surcroît en macro-zoom, dans le ventre cosmopolite et brouhaha de la métropole. Avec un bond dans le temps et dans I'espace, une nouvelle de Jean-Pierre April nous projette quelque part dans le puzzle indochinois, tiraillé par la fièvre d'après-guerre et celle-là plus persistante des bas-fonds de Hoi Tri. Puis, une énumération poétique et imagée au coeur de l'inversion révélatrice, signée Lina Remon, avant de passer à un vieux routier de souche citadine qui a choisi de vivre en Gaspésie et qui vient nous offrir, à sa façon, un réquisitoire de dernière chance qui oscillera bientôt vers une véritable osmose entre l'homme et l'animal, en l'occurence ici le Caribou devenant peu à peu un véritable sauf-conduit pour l'être humain. De son côté, Alain Saint-Yves a mis subtilement dans une bouteille de très beaux moments et I'a jetée sur la mer des mots pour que nous puissions la réchapper et la boire. Un peu plus loin, dans les rues sales et "Cracker Jack" de son Corridor 01, vous serez littéralement (cela va de soi) charrié par les "flashs" de Jean-Marc Cormier; de la poésie-vérité à la Une.

Dans un autre ordre d'idées, Ginette Perron nous transporte de déchirure consciente en accalmie suave dans sa conviction convaincante de briser l'ennui. James Paulin nous présente trois textes dont chacun parle avec intensité et accentue la vision poétique et filtrée de l'existence. "La légende de l'aller-retour", vous 
connaissez? Sinon, Rémi Beland se chargera de vous la raconter et c'est ainsi que vous y trouverez un portrait de I'homme aux sentiments atteints de schizophrénie, tout à coup rassemblés, soudés sous l'impact de quelques révélations grandissantes. Puis, des poèmes-témoins de Michelle Dubois, des poèmes pour dire, pour crier, pour vider l'abcès, mais aussi pour chuchoter et réveiller doucement l'immobile. Pour terminer cet autre chapitre d'URGENCES, une suite en XVII tableaux de Denuis Saint-Yves où l'auteur se penche sur I'homme, donc sur lui-même, et creuse bien au delà des miroirs et de l'auto-analyse pour rejoindre l'état de conscience à vif.

Avec ce troisième numéro d'URGENCES, amis lecteurs, s'achève une première année consacrée à la diffusion des lettres Estquébécoises en même temps que la fin de l'abonnement pour tous ceux et celles qui s'étaient déjà intéressés à notre revue dès le premier numéro. Si les auteurs, encouragés par l'expansion de nos lettres régionales, se doivent d'alimenter encore et encore notre banque de textes, vous lecteurs, maillons essentiels de la continuité, êtes maintenant prêts à appliquer la règle de Troye pour vous infiltrer un peu plus dans la Cité littéraire de chez-nous. Pour se faire:

Primo: renouveler le plus tôt possible son abonnement, question de conserver de bonnes habitudes.

Secundo: diffuser la revue à sa façon pour en faire profiter les autres; URGENCES est un cadeau qui s'offre bien, surtout en abonnement... Pourquoi pas?

Tertio: Joindre, par les points proposés en Primo et secundo, I'utile à l'agréable et faire d'une pierre deux coups et plus, en contribuant à encourager des auteurs de l'Est du Québec qui ne demandent qu'à prendre leur place au soleil trop tiède de notre climat et sous les cieux incléments de notre région. En d'autres mots, contribuer à l'éclaircissement culturel de notre milieu. 